\title{
GAS-PARTICLE MIXTURE FLOW IN VARIOUS TYPES OF CONVERGENT-DIVERGENT NOZZLE
}

\author{
SATOSHI OKUDA AND WOO SIK CHOI \\ Department of Chemical Engineering, Doshisha University, \\ Kyoto 602
}

\begin{abstract}
The velocity and behavior of crowded particles in the flow of gas-particle mixture as related to the shape of a convergent-divergent nozzle were investigated. Calculated values of the velocity of particles accelerated with various types of nozzle were compared with the experimental results measured by the double-flash photographic method. It was found that the calculations and experiments were in good agreement within the error of experimental measurement.

On the other hand, by using the dimensional analysis method, the velocity of particles or the specific kinetic energy of particles was expressed as the function of the following parameters: particle size, particle density, nozzle geometry, and operating conditions for gas flow. It was also made clear that the velocity and behavior of particles through the nozzle strongly depend upon the mixing ratio and the nozzle geometry, particularly the geometry of inlet and throat.
\end{abstract}

\section{Introduction}

This research is part of a study on the grinding mechanism of the fluid-energy mill, in which particles are accelerated by high velocity gas and fractured by colliding with either the chamber wall or each other. Since the intensity of collision is dependent upon the velocity of particles, it is important to measure the particle velocity and to clarify particle behavior related to the grinding mechanism of the fluid-energy mill.

In recent years, there has been much work on gasparticle mixture flow, such as studies of the flow behavior of solid propellant in rocket nozzle $\mathrm{e}^{1,2,10}$ and the erosion damage at the walls of a nozzle ${ }^{5,6}$. Gasparticle mixture flow in the nozzle was also investigated theoretically or experimentally by $\operatorname{Rumpf}^{7,8 \text { ? }}$ and Schlaug ${ }^{9}$. However, it is insufficient to predict the velocity of crowded particles from the data of particle velocity measured with a single particle, owing to the interactions of particles. Also, the behavior of particles inside the nozzle, especially in the vicinity of the nozzle throat, has been little investigated. This work was undertaken to clarify the above problems, to investigate the effects of nozzle shape on the behavior of particles, and to examine the effects of parameters such as particle size, particle density, initial air pressure, and feed rate of particles on the velocity of particles.

Received February 28, 1977. Correspondence concerning this article should be addressed to S. Okuda.

\section{Experiments}

\section{1 Experimental apparatus}

The experimental apparatus used for this work is shown schematically in Fig. 1. The compressed air from compressor (1) is introduced from receiver tank (2) to mixing chamber (8) through dryer (4), air filter (5), flow meter (6), and pressure-regulating valve (7), while the testing material is supplied from vibrating feeder (10) to nozzle (12) mounted in the large testing chamber (18) $(600 \times 900 \times 1200 \mathrm{~mm})$, which is large enough to avoid disturbance of the mixture flow in the nozzle. Four sides of the testing chamber are covered with colorless transparent plate of polyacrylate. Figure 2 shows the dimensions and shape of nozzles used in this experiment in detail.

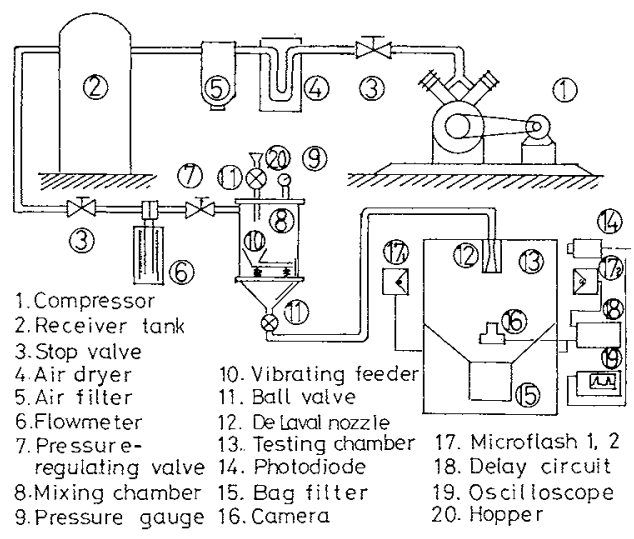

Fig. 1 Schematic diagram of experimental apparatus 
Table 1 Experimental ranges and testing materials

Experimental ranges Nozzle types: 4 kinds (Ref. Fig. 2) Air pressure: $2.0-5.0 \mathrm{Kg} / \mathrm{cm}^{2} \cdot \mathrm{G}$ Mixing ratio: $0.01-1.0$

\begin{tabular}{lccc}
$\begin{array}{c}\text { Testing } \\
\text { materials }\end{array}$ & $\begin{array}{c}\text { Density } \\
{\left[\mathrm{g} / \mathrm{cm}^{3}\right]}\end{array}$ & $\begin{array}{c}\text { Diameter* } \\
{[\mu \mathrm{m}]}\end{array}$ & Shape \\
\hline Impact resist & 1.05 & 1095 & Sphere \\
Polystyrene & 1.05 & 775 & $" \prime$ \\
& 1.05 & 545 & $" \prime$ \\
& 1.05 & 324 & $" \prime$ \\
Glass beads & 2.50 & 775 & $" \prime$ \\
Copper & 7.14 & 545 & $\prime \prime$
\end{tabular}

* Particle diameter indicates the arithmetic mean of JIS sieve opening of $\sqrt[4]{2}$ series.

\subsection{Testing material}

Spherical, impact-resistant polystyrene (PS) particles were used in most of the experiments because of their excellent resistance to fracture during experiments. In part, glass beads and copper particles were also used to investigate the effects of the density of material. Testing materials were repeatedly classified and made uniform with JIS standard sieves.

\section{3 Experimental technique and procedure}

1) The measuring technique of the velocity of particles The velocity of particles was measured by the double-flash photographic method. The schema of experimental arrangement and a typical experimental photograph are shown in Fig. 3 and Fig. 4, respectively.

As illustrated in the photograph of Fig. 4, the measurement of particle velocity was carried out by the following procedure. First, the time interval between two microflashes is set with delay circuit and confirmed with counter and oscilloscope. Next, the length of flying path of a particle for a known time interval is directly measured on the photograph, and the direction of its movement is easily distinguished by tracing the flying path of the particle.

2) Experimental procedure The experimental procedure consists of the adjustment of air flow rate and solid feed rate, the measurement of particle velocity, the observation of collision, and the collection of particles with bag filter. The air flow rate was controlled by adjusting the pressure-regulating valve. The experimental ranges and the testing materials are shown in Table 1.

\section{Experimental Results and Considerations}

2. 1 The flow behavior of particles related to the shape of nozzle

1) Experimental results on flow pattern It was confirmed that the behavior of particles in the nozzle strongly depends upon the nozzle shape and the operating conditions. Figure 5 shows the flow pattern
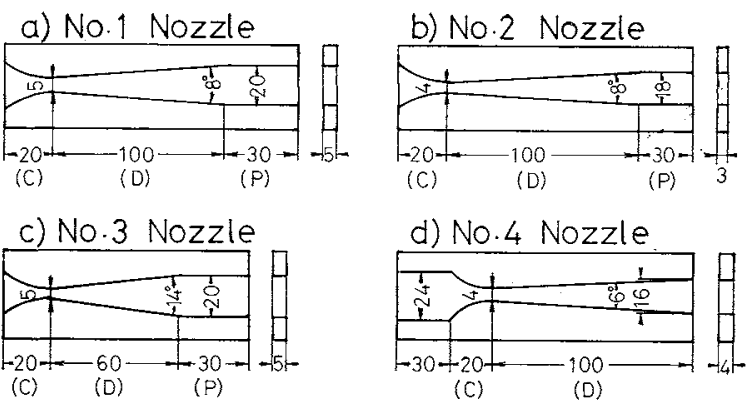

(C) Convergent part

(P) Parallel part

(D) Divergent part

Fig. 2 Nozzle geometry used in the experiments

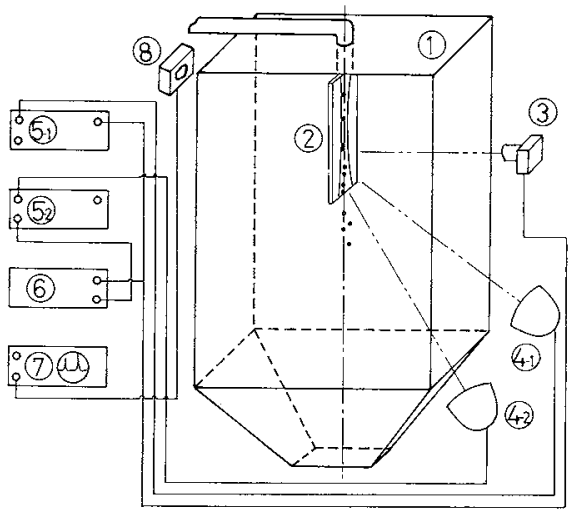

(1) Testing chamber (2) De Laval nozzle

(3) Camera (4) Microffash lamp 1, 2 (5) Microflash driver 1, 2 (6) Delay circuit (7) Oscilloscope (8) Photodiode

Fig. 3 Arrangement of experimental instruments for the measurement of particle velocity

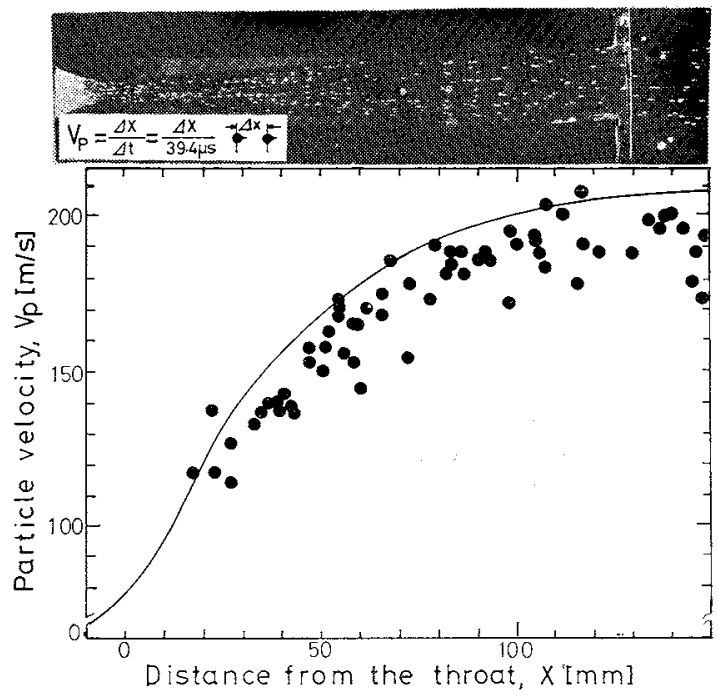

Line denotes the calculated values of particle velocity in the case of $m<0.1$.

Experimental conditions of photograph Nozzle No. 1, Initial air pressure: $4.0 \mathrm{Kg} /$ $\mathrm{cm}^{2}$ G., Mixing ratio: 0.33 [-], Testing material: $545 \mu \mathrm{m}$ PS, Time interval between two microflashes: $39.4 \mu \mathrm{s}$

Fig. 4 Typical photograph of particle trajectory and particle velocity at each position of nozzle 

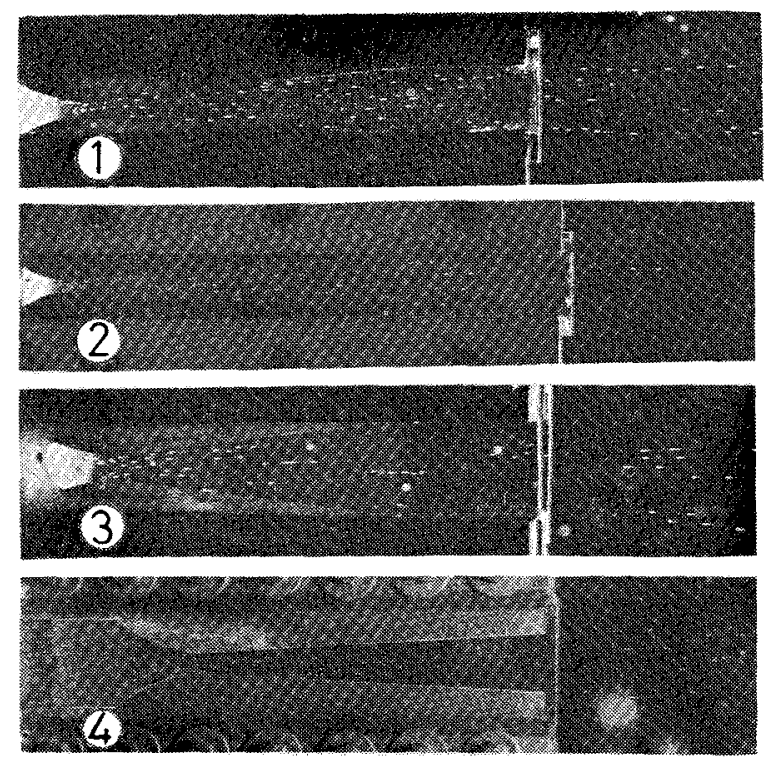

$m<0.1$
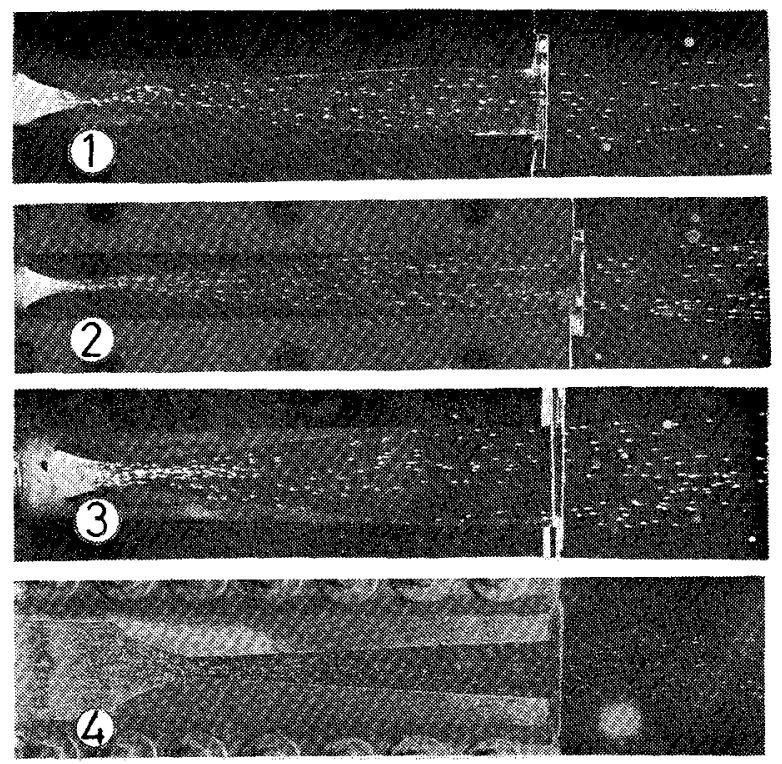

$m>0.3$

The number on photo corresponds to the types of nozzle in Fig. 2

Fig. 5 Flow pattern of particles for various types of nozzle

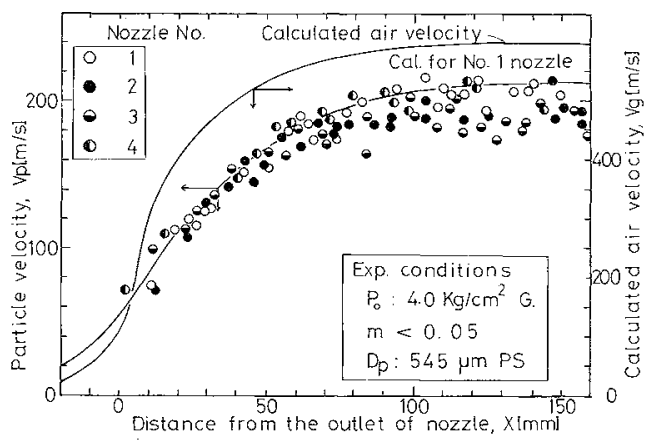

Fig. 6 Particle velocity distribution for various types of nozzle

of particles related to various types of nozzle. The behavior of particles changed remarkably in each flow region of the nozzle, such as the convergent region, the vicinity of throat, the divergent region (supersonic region), and the free space region after the nozzle outlet.

In the convergent region of the nozzle, the particles are introduced into the throat along the nozzle wall by the rapidly accelerated air flow. Although the micro-random motion of particles in the convergent region of the nozzle could not be obviously taken on the photographs, such a random motion was visible to the naked eye. In the vicinity of the throat, the particles turn their progressive ways along the contour of the throat from a convergent toward a divergent direction. It is considered that this rapid turning of direction makes particles collide with or rub each other more frequently. In the divergent region, most of the particles flow along the nozzle wall. The flow of particles very near the nozzle wall collides with the parallel contour of the wall at the rear part of the divergent region, so that their flying paths are seen to be curved toward the center of the nozzle as shown in photograph (2) of Fig. 5. It is noteworthy that the parallel part of the nozzle has a great influence upon the flow direction of particles after the nozzle outlet.

Although the behavior of particles before the throat could not be considered as one-dimensional flow, it was confirmed by experiment that the flow of gasparticle mixture after the throat could be appoximately recognized as one-dimensional and uniform velocity distribution flow.

2) Experimental results on the particle velocity The velocity of particles is defined as the mean value of particle velocities at each cross-sectional area of the nozzle. Figure 6 shows the measured velocity of particles related to the shape of the nozzle. The velocity of particles was also measured under various operating conditions. In Table 2 , the measured values of particle velocities are compared with the values of particle velocities calculated by Eq. (1) mentioned in the following section.

3) Comparison between experimental data and calculated values $B y$ assumptions used in the previous study $^{\mathrm{z}, 10)}$, the equation of particle motion for steady frictionless nozzle flow can be described as follows:

$$
V_{p} \frac{d V_{p}}{d x}=\frac{3 \rho_{g} C_{D}}{4 \rho_{p} D_{p}}\left(V_{g}-V_{p}\right)^{2}
$$

The velocity of gas flow along variable area of nozzle is expressed as follows ${ }^{3}$ :

$$
\frac{d V_{g}}{V_{g}}\left(M_{a}^{2}-1\right)=\frac{d A}{A}
$$


Table 2 Particle velocity for various types of nozzle and operating conditions

\begin{tabular}{|c|c|c|c|c|c|c|c|c|c|c|}
\hline \multirow{2}{*}{$\begin{array}{l}\text { Nozzle No. } \\
\text { \& Ref. No. } \\
1\end{array}$} & \multirow{2}{*}{ 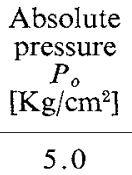 } & \multirow{2}{*}{$\begin{array}{c}\begin{array}{c}\text { Particle } \\
\text { density }\end{array} \\
{\left[\begin{array}{l}\rho_{p} \\
{\left[\mathrm{~g} / \mathrm{cm}^{3}\right]}\end{array}\right.} \\
1.05\end{array}$} & \multirow{2}{*}{$\begin{array}{c}\text { Particle } \\
\text { size } \\
D_{p} \\
{[\mathrm{~mm}]} \\
0.545\end{array}$} & \multirow{2}{*}{ 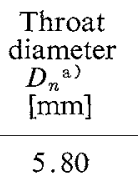 } & \multirow{2}{*}{$\begin{array}{c}\text { Distance } \\
\qquad \begin{array}{c}X \\
{[\mathrm{~mm}]}\end{array} \\
55\end{array}$} & \multicolumn{2}{|c|}{$\begin{array}{c}\text { Particle velocity } \\
\text { (Calc.) }{ }_{V_{p}} \text { (Exp.) } \\
{[\mathrm{m} / \mathrm{s}]}\end{array}$} & \multicolumn{2}{|c|}{$\begin{array}{c}\text { Function } \\
\begin{array}{l}(1) \\
\left.\left.\phi_{1}{ }^{b}\right) \times 10^{2}, \phi_{2} \mathrm{c}\right) \\
{[-]}\end{array}\end{array}$} & \multirow{2}{*}{$\begin{array}{c}\text { Coeff. } \\
(1) /(2) \\
{[-]} \\
1.16\end{array}$} \\
\hline & & & & & & 175 & 173 & 5.08 & 4.38 & \\
\hline 1 & 5.0 & 1.05 & 0.545 & 5.80 & 105 & 207 & 210 & 7.49 & 6.62 & 1.13 \\
\hline 1 & 5.0 & 1.05 & 0.545 & 3.76 & 55 & 171 & 163 & 4.51 & 4.12 & 1.09 \\
\hline 2 & 5.0 & 1.05 & 0.545 & 3.76 & 105 & 201 & 191 & 6.19 & 6.23 & 0.99 \\
\hline 3 & 5.0 & 1.05 & 0.545 & 5.75 & 55 & 169 & 168 & 4.79 & 4.37 & 1.10 \\
\hline 3 & 5.0 & 1.05 & 0.545 & 5.75 & 105 & 176 & 184 & 5.75 & 6.61 & 0.87 \\
\hline 4 & 5.0 & 1.05 & 0.545 & 4.79 & 55 & 175 & 176 & 5.26 & 4.26 & 1.23 \\
\hline 4 & 5.0 & 1.05 & 0.545 & 4.79 & 105 & 207 & 203 & 6.99 & 6.45 & 1.08 \\
\hline 1 & 5.0 & 1.05 & 1.095 & 5.80 & 55 & 134 & 131 & 2.91 & 2.54 & 1.15 \\
\hline 1 & 5.0 & 1.05 & 1.095 & 5.80 & 105 & 159 & 156 & 4.13 & 3.84 & 1.08 \\
\hline 1 & 5.0 & 1.05 & 0.775 & 5.80 & 55 & 154 & 156 & 4.13 & 3.32 & 1.24 \\
\hline 1 & 5.0 & 1.05 & 0.775 & 5.80 & 105 & 182 & 176 & 5.26 & 5.03 & 1.05 \\
\hline 1 & 5.0 & 1.05 & 0.324 & 5.80 & 55 & 205 & 210 & 7.49 & 6.57 & 1.14 \\
\hline 1 & 5.0 & 1.05 & 0.324 & 5.80 & 105 & 247 & 250 & 10.61 & 9.93 & 1.07 \\
\hline 1 & 5.0 & 2.50 & 0.775 & 5.80 & 55 & 111 & 106 & 1.91 & 1.40 & 1.36 \\
\hline 1 & 5.0 & 2.50 & 0.775 & 5.80 & 105 & 133 & 125 & 2.65 & 2.11 & 1.26 \\
\hline 1 & 5.0 & 7.14 & 0.545 & 5.80 & 55 & 73 & 62 & 0.65 & 0.65 & 1.00 \\
\hline 1 & 5.0 & 7.14 & 0.545 & 5.80 & 105 & 88 & 78 & 1.03 & 0.97 & 1.06 \\
\hline 1 & 4.0 & 1.05 & 0.545 & 5.80 & 55 & 161 & 154 & 4.03 & 3.50 & 1.15 \\
\hline 1 & 4.0 & 1.05 & 0.545 & 5.80 & 105 & 191 & 173 & 5.08 & 5.29 & 0.96 \\
\hline 1 & 3.0 & 1.05 & 0.545 & 5.80 & 55 & 144 & 128 & 2.78 & 2.63 & 1.06 \\
\hline 1 & 3.0 & 1.05 & 0.545 & 5.80 & 105 & 171 & 152 & 3.92 & 3.98 & 0.99 \\
\hline Ref. 5) & 8.0 & 4.01 & 0.210 & 25.40 & 76 & - & 180 & 5.50 & 5.82 & 0.95 \\
\hline Ref. 5) & 8.0 & 4.01 & 0.210 & 25.40 & 51 & - & 154 & 4.03 & 4.51 & 0.95 \\
\hline Ref. 8) & 1.5 & 2.22 & 0.157 & 3.00 & 30 & - & 60 & 0.61 & 0.86 & 0.71 \\
\hline Ref. 9) & 8.0 & 7.80 & 0.794 & 10.00 & 100 & - & 85 & 1.23 & 1.11 & 1.10 \\
\hline Ref. 9) & 8.0 & 7.80 & 0.794 & 10.00 & 50 & - & 60 & 0.61 & 0.85 & 0.61 \\
\hline
\end{tabular}

a) $D_{n}$ : Diameter of the circle which has the same area as the rectangular cross-sectional area of nozzle.

b) $\phi_{1}=\left(V_{p}^{2} / 2 C_{p g} T_{g 0}\right) \quad$ c) $\phi_{2}=(\gamma-1 / \gamma)\left(X / D_{n}\right)^{0.64} \cdot\left(D_{p} / D_{n}\right)^{-0.78} \cdot\left(\rho_{g o} / \rho_{p}\right)$

The calculation of particle velocity was carried out based on the following conditions: 1) the initial particle velocity at the inlet of the convergent region of the nozzle is $20 \mathrm{~m} / \mathrm{s}$ (the calculated particle velocity scarecely varied with inlet particle velocity in the range of $10 \mathrm{~m} / \mathrm{s}$ to $30 \mathrm{~m} / \mathrm{s}$.); 2) the initial temperature of air in the mixing chamber is $293 \mathrm{~K}$; 3) shock waves do not occur at any position in the nozzle before the parallel part of the nozzle; 4) the mixing ratio, defined as the ratio of mass feed rate of particles to mass flow rate of gas, is very low, so that the presence of particles has no influence on the motion of particles; 5) the value of drag coefficient $C_{D}$ in the range of supersonic region after the nozzle throat is 1.0 , based on May's paper ${ }^{4}$. From May, the coefficient $C_{D}$ is about 1.0 over the range of Mach number from 1.0 to 3.0 and Reynolds number from $10^{3}$ to $10^{4}$. Figure 6 shows also calculated value of the particle velocity for the number 1 nozzle. As shown in Fig. 6, the experimental results for various types of nozzle agreed well with the calculated values within the error of experimental measurement. One standard deviation of particle velocity at $105 \mathrm{~mm}$ distance from the throat of nozzle was $6.7 \mathrm{~m} / \mathrm{s}$. 4) Considerations about the shape of nozzle From the results on the velocity of particles as shown in Figs. 5 and 6, it was found that nozzle shape has considerable influence upon the acceleration of particles along the divergent region of the nozzle. The whole angle of the divergent wall of the nozzle is closely associated with the frequency of collision when particles pass through the nozzle, while the length of the divergent region is strongly related to particle acceleration. Thus it was confirmed that the optimum shape of nozzle for particle acceleration has the following dimensions: the whole angle of divergent wall is from $6^{\circ}$ to $10^{\circ}$, and the length of divergent region is from $100 \mathrm{~mm}$ to $130 \mathrm{~mm}$ for accelerating coarse particles, while a length of less than $100 \mathrm{~mm}$ is sufficient for fine particles.

\section{2 Parameters having an effect on the velocity of particles}

When the mixing ratio is low, it is considered that particle size, particle density, and initial air pressure are main parameters having an effect on particle velocity. The experimental results for these parameters are shown in Figs. 7, 8, and 9. Figure 7 shows the influence of particle size, Fig. 8 the influence of particle density, and Fig. 9 the influence of initial air pressure in mixing chamber (8). Experimental results 


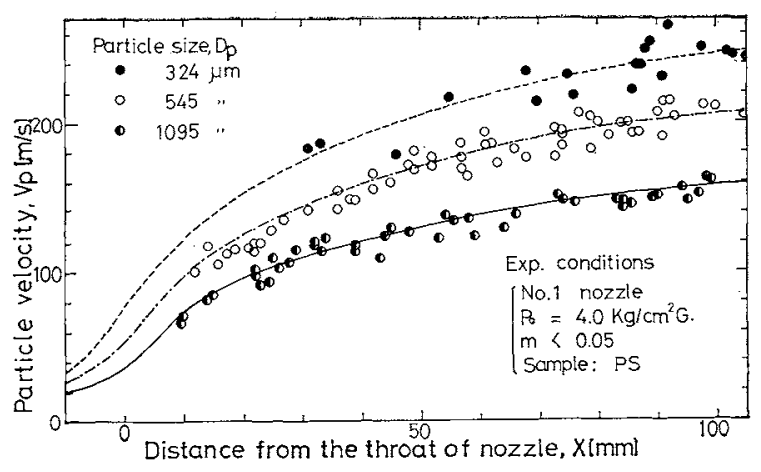

Lines denote the calculated values of $V_{p}$.

Fig. 7 Particle velocity related to the particle size

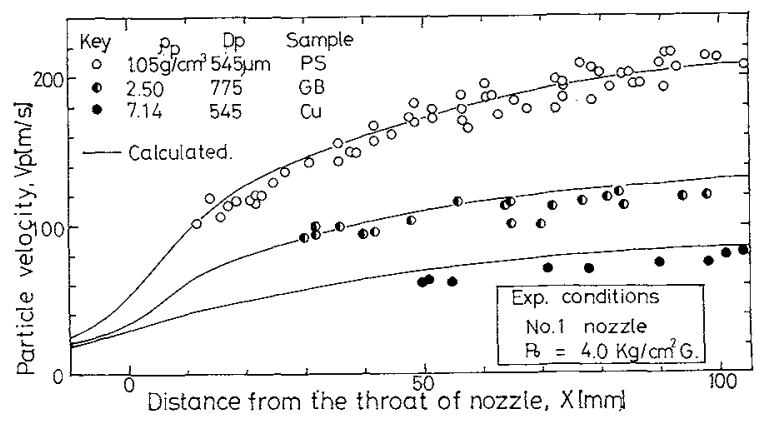

Fig. 8 Particle velocity related to the density of particle

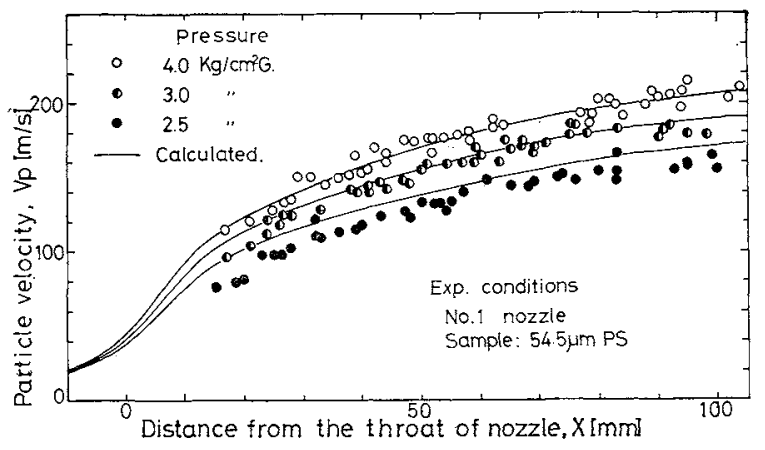

Fig. 9 Particle velocity related to the initial air pressure

for the above parameters agreed well with calculated values within the error of experimental measurement.

\section{The Formulation of Particle Velocity}

Most of the data mentioned above were measured for the case of low mixing ratio. When the mixing ratio is low and the interaction between particles is negligible, particle velocity can be predicted by Eq. (1). However, such a calculation is very troublesome, and the effect of gas-particle mixing ratio on particle velocity is not taken into account in Eq. (1). Accordingly, expression of experimental results of particle velocity in a simple formula was tried. The parameters having an effect on particle velocity such as particle size, particle density, initial air pressure, and mixing ratio should be taken into account in this

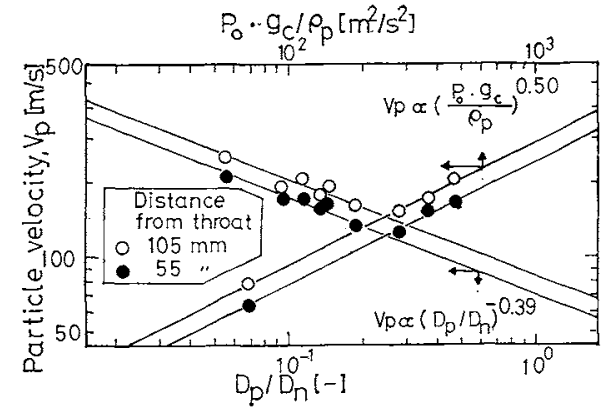

Fig. 10 Particle velocity related to $\left(D_{p} / D_{n}\right)$ and $\left(\boldsymbol{P}_{0} \boldsymbol{g}_{c} / \boldsymbol{\rho}_{p}\right)$

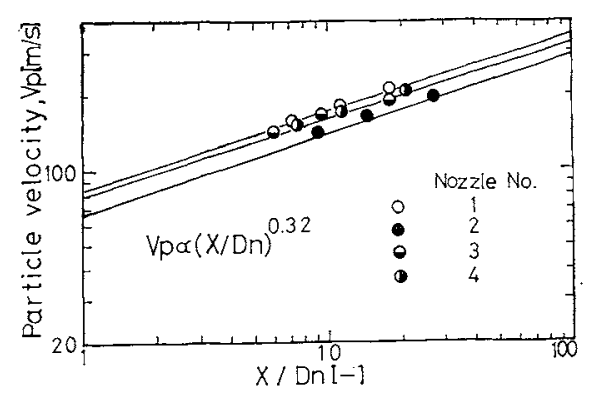

Fig. 11 Particle velocity related to $\left(X / D_{n}\right)$

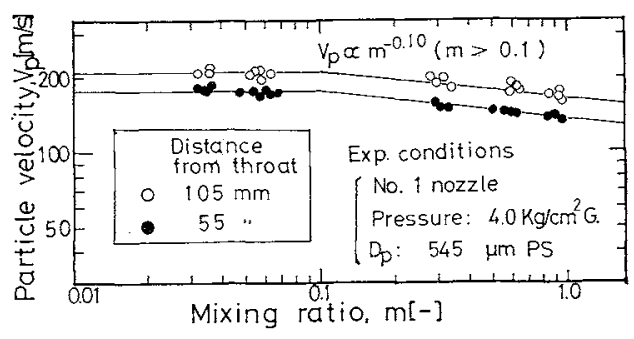

Fig. 12 Particle velocity related to the mixing ratio

formula. The particle velocity may be considered as a function of the following variables;

$$
V_{p}=\phi\left(X, D_{n}, D_{p}, \rho_{p}, P_{o}, W_{p}, W_{g}\right)
$$

A conventional dimensional analysis using the Rayleigh index method has yielded the relationship that particle velocity in the nozzle can be described as follows:

$$
V_{p} \cdot\left(\frac{P_{0} g_{o}}{\rho_{p}}\right)^{-1 / 2}=\phi\left\{\left(\frac{X}{D_{n}}\right)^{a} \cdot\left(\frac{D_{p}}{D_{n}}\right)^{b} \cdot\left(\frac{W_{p}}{W_{g}}\right)^{c}\right\}
$$

The values of exponents, $a, b$, and $c$ of dimensionless groups in the function $\phi$ were obtained from data of velocities of particles at a distance of $55 \mathrm{~mm}$ and $105 \mathrm{~mm}$ from nozzle throat. Figure $\mathbf{1 0}$ shows particle velocity related to the dimensionless group $\left(D_{p} / D_{n}\right)$ and the dimension group $\left(P_{0} g_{c} / \rho_{p}\right)$. Figure 11 shows the relationship between particle velocity and the dimensionless group $\left(X / D_{n}\right)$. Figure 10 shows that the exponent of dimension group $\left(P_{o} g_{c} / \rho_{p}\right)$ coincides with 0.50 , which is derived from the dimensional analysis as shown in Eq. (4). Figure 12 
is a plot of the relation between particle velocity and mixing ratio, and shows that particle velocity hardly varies with mixing ratio in the range of $m<0.1$, while over the range of $m \geqq 0.1$, it decreases by the exponent, -0.10 with increase of $m$. Therefore, it is reasonable that when the mixing ratio is less than 0.1 , its effect on particle velocity can be negligible. The group $\left(P_{o} g_{c} / \rho_{p}\right)$ on the left side of Eq. (4) can be transformed into the group $\left\{(\gamma-1 / \gamma) \cdot C_{p g} \cdot T_{g o} \cdot \rho_{g o} / \rho_{p}\right\}$ from the state equation of ideal gas at stagnation point in order to express how much the stagnation enthalpy of gas is converted into kinetic energy of particles. Thus, Eq. (4) can be summarized as follows:

$$
\frac{V_{p}^{2}}{2 C_{p g} T_{g o}}=k_{1}\left(\frac{\gamma-1}{\gamma}\right) \cdot\left(\frac{X}{D_{n}}\right)^{0.84} \cdot\left(\frac{D_{p}}{D_{n}}\right)^{-0.78} \cdot \underset{(m<0.1)}{\left(\frac{\rho_{g o}}{\rho_{p}}\right)}
$$

and

$$
\begin{aligned}
\frac{V_{p}^{2}}{2 C_{p g} T_{g o}}= & k_{2}\left(\frac{\gamma-1}{\gamma}\right) \cdot\left(\frac{X}{D_{n}}\right)^{0.64} \cdot\left(\frac{D_{p}}{D_{n}}\right)^{-0.78} \cdot\left(\frac{\rho_{g o}}{\rho_{p}}\right) \\
& \times m^{-0.20} \quad(m \geqq 0.1)
\end{aligned}
$$

where the dimensionless group $\left(V_{p}^{2} / 2 C_{p g} T_{g o}\right)$ on the left side of above equations expresses the specific kinetic energy of particles per unit stagnation enthalpy of air, in other words the specific energy efficiency, for accelerating particles with given nozzle and operating conditions. Each dimensionless group on the right side has a physical meaning as follows. $\left(X / D_{n}\right)$ expresses the shape characteristics of nozzle, $\left(D_{p} / D_{n}\right)$ the ratio of particle size and throat diameter, and $\left(\rho_{g o} / \rho_{p}\right)$ the density ratio of air at stagnation point and solid particle. The value of coefficient $k_{1}$ in Eq. (5) is 1.06 , and the value of the coefficient $k_{2}$ Eq. (6), whose value is 0.669 , is obtained from the condition that Eq. (6) coincides with Eq. (5) at $m=0.1$.

In addition to the results of this experiment, the data reported by other researchers, Neison and Gilchrist ${ }^{5}$, Rumpf $^{8}$, and Schlaug ${ }^{9}$, are calculated by Eq. (5), and shown in Fig. 13 and in Table 2. In spite of being obtained under various experimental conditions, they are in good agreement with this experimental result. Therefore, it is considered that Eq. (5) or Eq. (6) is very convenient for predicting the particle velocity for gas-particle mixture flow in a nozzle.

\section{Conclusions}

The velocity and behavior of particles in the flow of gas-particle mixtures related to various types of nozzle were investigated with the double-flash photographic method.

1) The particle velocity calculated by Eq. (1), based on frictionless adiabatic flow in a convergentdivergent nozzle, was in good agreement with experimental results.

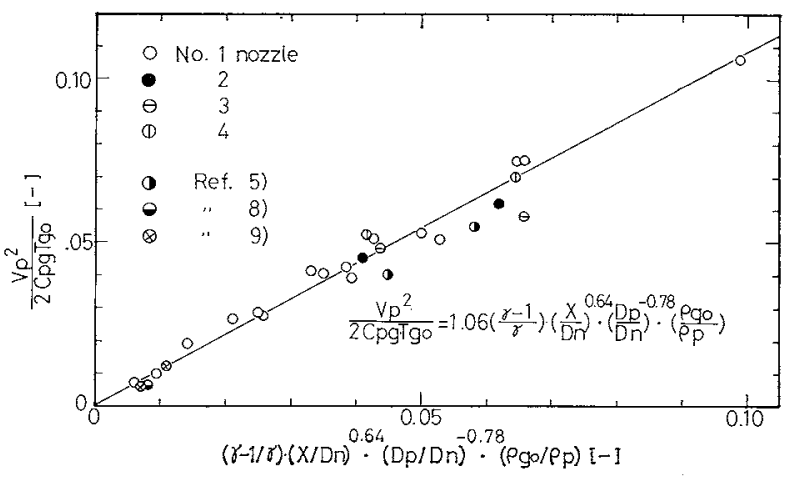

Fig. 13 Relationship between $\left\{V_{p}^{2} / 2 C_{p g} T_{g o}\right\}$ and $\left.(\gamma-1 / \gamma)\left(X / D_{n}\right)^{0.84}\left(D_{p} / D_{n}\right)^{-0.78}\left(\rho_{g o} / \rho_{p}\right)\right\}$

2) A simple formula for particle velocity was obtained in the form of Eq. (5) or Eq. (6) with dimensional analysis from experimental results. This formula is convenient for predicting the velocity of particles in gas flow in a convergent-divergent nozzle.

3) The flow behavior of gas-particle mixtures was made clear, in particular, in the vicinity of the nozzle throat. From these considerations the optimum nozzle shape for accelerating particles was found.

\section{Acknowledgment}

This work was supported by a Grant-in-Aid for Fundamental Scientific Research from the Ministry of Education.

The authors wish to express their gratitude to Nippon Pneumatic Mfg. Co. for the manufacture of the experimental equipment and the assistance of their colleagues.

\section{Nomenclature} $C$ $C_{D}$

$C_{p q}$

$D_{n}$

$D_{p}$

$g_{c}$

$k_{\text {I }}$ $k_{1}$
$k_{2}$
$M a$ $m$

$P_{g}$ $P_{g}$
$T_{g}$

$T_{g}$
$V_{g}$

$V_{g}$
$V_{g}$

$V_{p}$
$W_{g}$

$W_{g}$

$X$

$\begin{array}{ll}\phi & =\text { function } \\ \gamma & =\text { adiabatic constant of gas }\end{array}$

$\rho_{g} \quad=$ density of gas

$\rho_{p} \quad=$ density of particle

$\left[\mathrm{kg} / \mathrm{m}^{3}\right]$

$\langle$ Subscript〉

$o \quad=$ refers to stagnation condition

\section{Literature Cited}

1) Baily, A. B. and J. Hiatt: AIAA J., 10, 1436 (1972).

2) Kliegel, J. R.: 9th Symposium (International) on Com- 
bustion, p. 811 (1963).

3) Liepmann and Roshko: "Elements of Gas Dynamics", p. 127, John Wiley \& Sons, Inc. (1957).

4) May, A.: J. Appl. Phys., 28, 910 (1957).

5) Neilson, T. H. and A. Gilchrist: J. Fluid Mech., 33, 131 (1968).

6) Neilson, T. H. and A. Gilchrist: ibid., 35, 549 (1969).

7) Rumpf, H.: Chem-Ing-Tech., 32, 129 (1960).

8) Rumpf, H.: ibid., 32, 335 (1960).
9) Schlaug, H.: "Dechema Zerkleinern Symposion", p. 531, Verlag Chemie, Weinheim, und VDI-Verlag, Düsseldorf (1963).

10) Soo, S. L.: "Fluid Dynamics of Multiphase Systems", p. 277, Blaisdell Pub. Co., Mass. (1967).

(Presented at the 9th Autumn meeting of The Soc. of Chem. Engrs., Japan, at Fukuoka, Oct. 1975).

\title{
EXPERIMENTAL STUDY ON HEAT TRANSFER OF COMBINED FREE AND FORCED LAMINAR CON- VECTION IN THERMAL ENTRANCE REGION OF HORIZONTAL RECTANGULAR DUCTS
}

\author{
HAJIME NAKAMURA, AKIHIRo MATSUURA AND \\ JUMEI KIWAKI \\ Department of Mechanical Engineering, Daido Institute of \\ Technology, Nagoya 457 \\ SETSURo HIRAOKA AND IKUHO YAMADA \\ Department of Industrial Chemistry, Nagoya Institute of \\ Technology, Nagoya 466
}

\begin{abstract}
Experimental studies by the electrochemical method were made to investigate the heat transfer problems of combined free and forced laminar convection for high $\mathrm{Pr}$ fluid in the thermal entrance region of rectangular ducts with the aspect ratio $\gamma=0.5$, where the boundary condition of uniform wall temperature has been used.

Experimental data for the local and mean $\mathrm{Nu}$ were compared with analytical solutions obtained by developing Leveque's method and the numerical one, and the following conclusions were reached: i) for the region of forced convection in which the effect of free convection approaches zero, the experimental results are well-correlated with the analytical results obtained by developing Leveque's method; ii) for the region where the effect of free convection exists, the experimental results are in satisfactory agreement with the numerical ones; and iii) for the onset of free convection effects, both experimental and numerical results are also in good agreement with the original correlative equation suggested by $\mathrm{Ou}$ et al.
\end{abstract}

\section{Introduction}

For the design of compact heat exchange equipment, it is very important to study the heat transfer problems of noncircular ducts. It is well known ${ }^{5}$ ) that the heat transfer problems in the thermal entrance region for laminar flow with uniform wall temperature can be reduced to the Graetz problem ${ }^{2)}$ for the circular tube and noncircular ducts. These problems have been investigated by many workers. Dennis et al. ${ }^{11}$ and Montgomery et al. ${ }^{91}$ suggested

Received January 30,1978. Correspondenc econcerning this article should be addressed to H. Nakamura. analytical solutions of the Graetz problem for rectangular ducts. The effect of free convection, however, was not included in these solutions. Recently, Ou et $a .^{111}$ presented numerical solutions for the Graetz problem of combined free and forced laminar convection for high-Prandtl number fluid under the boundary condition of uniform wall temperature in the horizontal rectangular duct. On the other hand, experimental studies of these problems have scarcely been published.

The difficulty of experimental research in these problems may lie in the fact that it is very difficult to satisfy the following three items: 